\title{
Direct computation on the kinetic spectrophotometry
}

Hansen, J.; Broer Pedersen, P.

Publication date:

1974

Document Version

Publisher's PDF, also known as Version of record

Link back to DTU Orbit

Citation (APA):

Hansen, J., \& Broer Pedersen, P. (1974). Direct computation on the kinetic spectrophotometry. Risø National Laboratory. Risø-M No. 1705

\section{General rights}

Copyright and moral rights for the publications made accessible in the public portal are retained by the authors and/or other copyright owners and it is a condition of accessing publications that users recognise and abide by the legal requirements associated with these rights.

- Users may download and print one copy of any publication from the public portal for the purpose of private study or research.

- You may not further distribute the material or use it for any profit-making activity or commercial gain

- You may freely distribute the URL identifying the publication in the public portal

If you believe that this document breaches copyright please contact us providing details, and we will remove access to the work immediately and investigate your claim 
Title and author(s)

Direct Computation on the Kinetic Spectrophotometry

Date March $10 \% 4$

$\frac{1}{1}$

by

Johnny $W$. Hansen and P. Broer. Pedersen

Department or group

Accelerator Dept.

Group's own registration numberis)

Abstract

Copies to

This report describes an analog computer de iigned for calculations of transient absorption from photographed recordings of the oscilloscope trace of the transmitted light intensity. The computer calculates the optical density OD, the natural logarithm of $O D$, and the natural logarithm of the difference between the limiting optical density 0Doo and the actual optical density, and the reciprocal of the optical density. The calculated values are displayed on a digital voltmeter or recorded on an XY-recorder. Accuracy and linearity of the individual computing circuits are discussed and the overall performance of the system is demonstrated. In the appendices a user's manual is given.

The computer was especially developed for analysing oscilloscope photos from radiation chemical pulsed radiolysis. 


\section{CONTPNTS}

Page

1.

Int roduction

1

2. Design Phil.jsophy $\ldots \ldots \ldots \ldots \ldots \ldots \ldots \ldots \ldots \ldots \ldots \ldots \ldots \ldots \ldots \ldots \ldots$

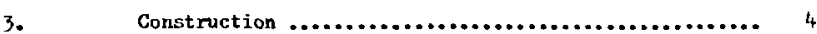

3.1 The Manually Operated XY-Curve Tracer .......... 4

3.2 Evaluation of the Optical Density D ........... 4

3.3 Computation of the Natural Logarithm of D ........ 8

3.4 Computation of the Reciprocal Value of D ........ 9

4.

Performanc

Reference

Appendix 1 Operating Instructions $\ldots \ldots \ldots \ldots \ldots \ldots \ldots \ldots \ldots \ldots \ldots, 12$

Appendix 2 Mairtenance Instruction ......................... 19

Fig. 9 Computation Non-Linearity ..................... 23

Fig. $10 \quad$ Block Diagram .............................. 24

Fig. 11 Complete Diagram, Computing Circuits ............... 25

Fig. 12 Diagram, Power Supply ......................... 26

Tabie 1 Table of the Functions $\ldots . . . \ldots \ldots \ldots \ldots \ldots \ldots \ldots \ldots$ 27

Table 2 Printed Board Connector ......................... 28 


\section{INTRODUCTION}

In spectroscopic investigation of short living chemical species, e.f. at pulse radiolysis, a light beam is widely used as the examination tool for observing changes in absorbance due to radicals formed by stopping of a high-energy electron beam in a transparent solution. The resulting time-dependent change in the transmitted light intensity is measured by a photomultiplier, the output of which is measured on an oscilloscope, fig. 1. The oscilloscope trace is photographed by means of a Polaroid camera, and from the picture investigations of the kinetics are carried out either manually with a ruler and subsequent calculations or by enlarging the photograph for automatic reading and mathematical treatment in a computer. This examination of the experimental results is tedious and laborious and cannot be performed during the experiments. By using the small computer to be described the most significant data can be derived immediately after the exposure. The computed data are either displayed on a digital voltmeter or plotted on an XY-recorder with the abscissa as the time axis.

The analog computer unit is relatively inexpensive to produce and the computing accuracy is within a few per cent, depesndent on the mode of operation, fig. 8.

\section{DESIGN PHILOSOPHY}

In a pulse radiolysis system the sample, a transparent chemical solution contained in a small glasscell, is irradiated by a single pulse of electrons from an accelerator. An analysing light passes through the solution into a monochromator and a photomultip? ier, fig. 1. The converted light intensity signal from the photomultiplier is during - and a few microseconds after - the electron pulse observed on an oscillascope. 
and rovide an optical density range of 0.01 to 1.0 . The curve tracer feeding the computer from the oscilloscope photograph should be manually operated and designed for photos with an overall size of $31 / 4 \times 41 / 4$ inches, and with the trace within an area of $5 \times 10 \mathrm{~cm}$.

The specifications of calculation accuracy should hold for a room temperature of $20^{\circ} \mathrm{C}-5^{\circ} \mathrm{C},+10^{\circ} \mathrm{C}$. The equipment should be easy to operate, and inexpensive in fabrication.

\section{CONSTRICTIION}

\subsection{The Manually Operated XY-Curve Tracer}

The manually operated curve traler is a moving board with a fixed-position pointer. The hoard is fitted with two potentiometers as Iinear transducers for the $X$ and $Y$ coordinates. The $X$-axis potentiometer, $10 \mathrm{~cm}$ long, and the $Y$-axis potentiometer, $5 \mathrm{~cm}$ long, are $1 \mathrm{k \Omega} \pm 5 \%$ wire-wound sliding potentioneters with linearity of $\pm 0.4 \%$ and a resolution of $1.1 \%$ and $2 \%$ respectively of the total resistance. The potentiometers are fed from a lo $V$ dc reference voltage generator. The output voltage from the potentiometer at the $X$ coordinate, the time axis, is fed directly to the output terminal, the loading of which should not be less than $25 \mathrm{k} \Omega$.

\subsection{Evaluation of the Optical Density D}

In the calculation of the optical density it was a requirement that photographs with scale factors up to 5 could be prepared. This in fact might be regarded as a change in the loo\% light intensity $I_{0}$ and thus a change in the voltage to the Y-axis potentiometer.

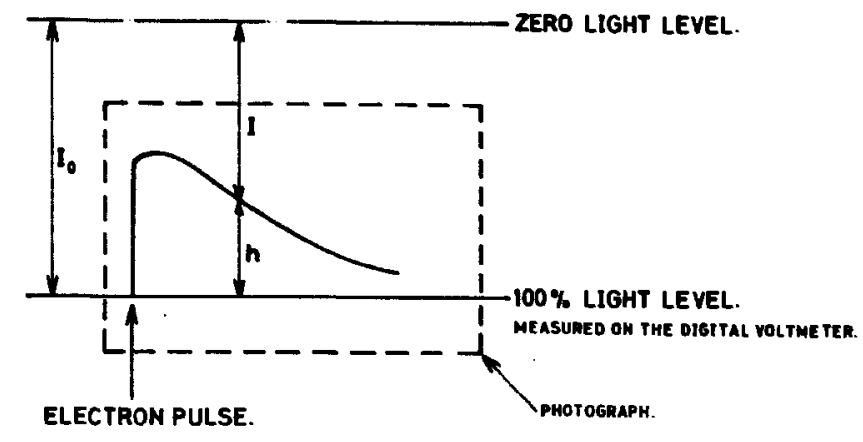

FIG.2.

$$
\begin{aligned}
& D=-\log \frac{1}{T} ; \quad T=\frac{I_{0}}{T}=\frac{I}{I_{0}-h} ; \\
& D=-\log \frac{I_{0}-h}{I_{0}}=-\log \left(1-\frac{h}{I_{0}}\right) ;
\end{aligned}
$$

By incorporating the scale factor $Q$ into $I_{0}$, the look light level, $I_{0}$ may be written as: $I_{0}=Q+I_{0}^{\prime}$ and $D=-\log \left(1-\frac{h}{Q+I_{0}^{\prime}}\right)$.

The electrical analog to the equation apart from the negative sign is shown in fig. 3 :

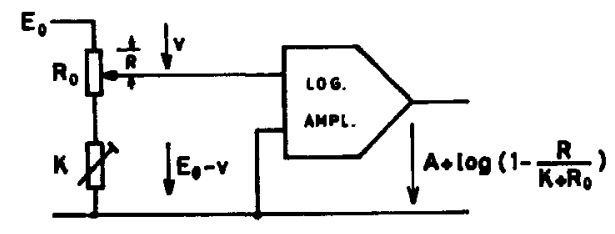

FIG.3.

$E_{0}-v=E_{0}\left(1-\frac{R}{K+R_{0}}\right) ; \quad \log \left(E_{0}-v\right)=\log E_{0}+\log \left(1-\frac{R}{K+R_{0}}\right) ;$ for $E_{0}=1=\log \left(E_{0}-v\right)=\log \left(1-\frac{R}{k+R_{0}}\right)$; 
The absorption range of $0.01 \leq 1 \leq 0.9$ gives an optical density variation of $0.00436 \leq \mathbb{D} \leq 1.0$. In the electrical analog the logarithmic amplifier gives an output ranging from $4.36 \mathrm{mV}$ up to 1.0 volt. When using Philbrick-Nexus logarithmic module 4357 a linearity of $1 \%$ of reading is guaranteed. A rated offset voltage variation with temperature of $0.1 \mathrm{mV} /{ }^{\circ} \mathrm{C}$ results in an output voltage change of $2 \mathrm{mV}$ in the desired temperature range, or Sol of the minimua signal to be measured. By adequate trimming of the logarithmic amplifier a somewhat better linearity can be achieved, but the offiset voltage error is too big for acceptable operation. On accourt of this error the computation of the optical density in the lower range is performed by using the series representation of the natural logarithm function. This evaluation can easily be made accurate enough for values of the optical density overlapping the acceptable lower values of the logarithaic amplifier. The Maclaurin series representation of the base ten logarithm of the electrical analog signal is as follows:

$\log (1-x)=0.4343 \ln (1-x) \simeq 0.4343\left(-x-\frac{1}{2} x^{2}-\frac{1}{3} x^{3}-\ldots \ldots\right)$

$-\log \left(1-\frac{R}{K+R_{0}}\right)=0.4343\left(\frac{R}{K+R_{0}}\right)+0.2715\left(\frac{R}{K+R_{0}}\right)^{2}+0.1448\left(\frac{R}{K+R_{0}}\right)^{3}+\ldots$

By using a corrected constant (0.2736) for the second term and excluding the subseaguent terme the scries car be made to fit within 19 in the desired range. Fig. 4 shows the electrical network for the series generation of the same signal as fed to the logarithmic anplifier.

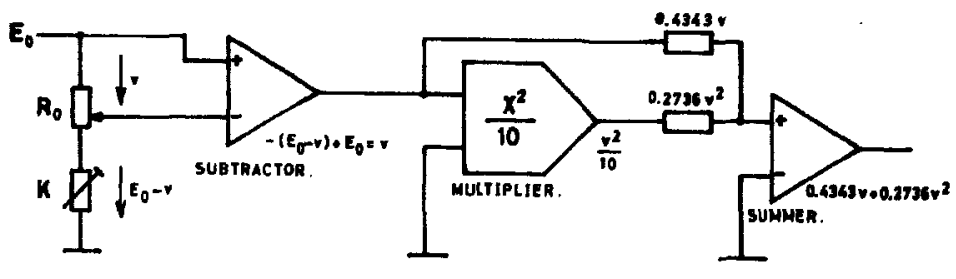

FIG.4.
A high accuracy multiplier, Analog Device: madel 4tik, ha.; a mated non-linearity of $0.0 \%$ of full scale deflection, which contributes to $0.13 \%$ of the accuracy of the smallest output signal. The output offset drift is $150 \mu V^{\prime}{ }^{\circ} \mathrm{C}$ which amounte to $3 \mathrm{mV}$ in the temperature range of operation. this offset error is in fact too big, but by increasing the input signal $v$ by a factor of 10 and division by 10 after multiplication and summing this influence is reduced to less than $2 \%$ of the smallest value of the optical density.

A combination of the two alternative methods of complting the optical density turns out to offer the most accurate and reliable performance. A high gain comparator driving a mercury-wetted, reed relay contact was adjusted to switch on a certain level of the input voltage $v$ where the curve; for the log. amplifier and the multiplier were considered to cross. Two comparators connected in a logic to sense both on the level of $\mathbf{v}$ and on the two output signals were found not to add to a more accurate operation because of a final accuracy by the manual operation of the curve tracer. The block diagram of fig. 5 shows the circuit for the evaluation of the optical density from the absorption response.

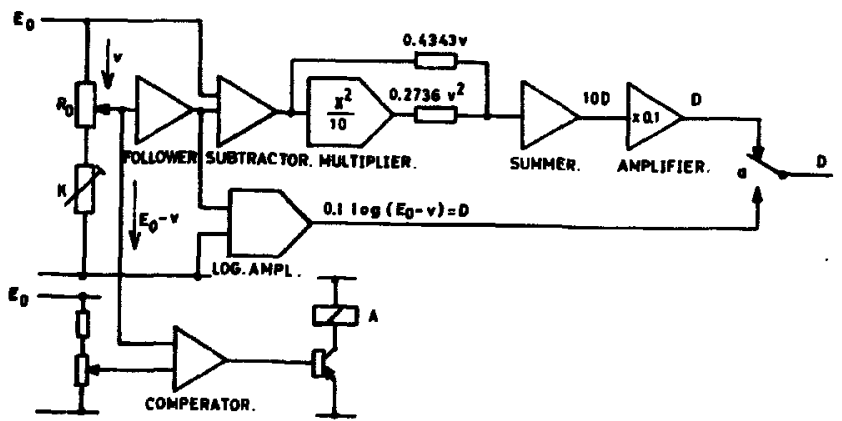

FIG.5. 
The reed relay, a Clare type HGKM- 17211 IOC, wi th mercury-wetted make before break contacts has no contact bounce, which is of great importance. A contact resigtance of 20 mohms will in a load resistance of 1 kohm exhioit a voltage error of $0.03 \%$.

By selecting the resistance value of the K-potentiometer to be 5 kohms a scale factor of 6 is obtained giving a maximum optical density per unit length of $0.016 \mathrm{D} / \mathrm{cm}$ on the $X Y-r e c o r d e r$. To avold loading of the $R_{0}$ and $X$ resistors by the subtractor a follower amplifier is used. The common mode rejection ratio of this amplifier must not be less than $86 \mathrm{~dB}$ to wake the error voltage diminishing.

\subsection{Computation of the Natural Logarithm of D}

In the mode of computing the natural logarithm of the optical density, $1 n D$, an error of about $5 \%$ of the reading $i_{i s}$ tolerated. This makes it possible to uce a Phillbrick/Nexus logaríthmic module 4357 followed by a Phillbrick/Nexus loogol operational amplifier, fig. 6.

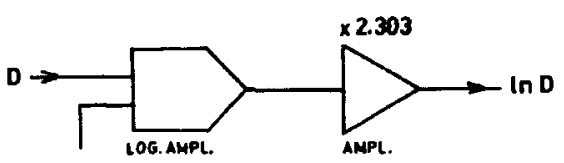

F16.6.

Here the offset voltage drift with temperature amounts to $2.5 \%$ of the smallest measured value of $\mathrm{lnJ}$ ) within the temperature range. The non-linearity is $1 \%$ of the reading.

The naturat Jofaritim of the difference between the limiting optical densily and the acturi optirn] derisity, $\ln \left(D_{\infty}-D\right)$, is performed by connecting a subtractor, fed from the circuit computing: $D$ and from a potentiometer giving Dos, in front of the logarithmic amplifier, fig. ?.

The voltage of Dos must be continuousily variable between o and 1.0 volt. In this computing mode a negative signal may be fed to the logaritlunic amplifier, making it reverse to a fully negative output, which may be a little confusing in operation. The accuracy of this operating mode is comparable with that of the $\operatorname{lnD}$ - mode.

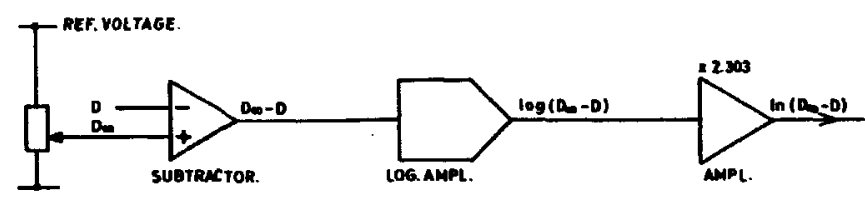

FIG.7.

\subsection{Computation of the Reciprocal Value of $D$}

The computation of one divided by the optical density, $1 / \mathrm{D}$, theoreticaliy means an output figure ranging from 1.0 to infinity as the optical density from 1.0 converges against zero. In the electrical analog the output voltage is limited to the dynamic range of the operational amplifiers and for the logarithmic module expecially to \pm lo volta. With a high accuracy multiplier in the division mode an accuracy as for the siquaring mode cannot be expected. For small voltage values of the denominator the non-linearity is increaned leentibe of the increased loop gain. The inaccuracy for the actual smallest value: of the denominator amounts to more than 20\%\%. Hy using a logarithmic morlule 1 the antilogarithmic mode of operation the inaccuracy is decreased to an a able amount. 
Fron the minimun optical derliaity to be measured corresponding to $4.36 \mathrm{my}$ and the assignmentsi of the logarithmic module $e_{\text {out }}=10^{-} e_{i n} \leq 1$ the output figure of $1 / \mathrm{p}$ has to be multiplied by a factor of $10^{-5}$. The mathematical computation to be performed $x i l l$ then be antilog $\left(\log 10^{-3}-\log 0.00436\right)=$ anti$\log (-3-(-2.359))=0.229$ correspanding to an output voltage of $229 \mathrm{mV}$. The conformity to the ideal logarithmic curve of the log. module in the antilogarithmic mode is guaranteed to be $1 \%$ of the reading, and the off set voltage drift in the temperature range ascount: for almost $20 \%$ of the smallest value of $1 / \mathrm{D}$. The performance specification of the law output voltages might be improved by the use of an oven for the antilog elemcnt. To increase the signal to noise ratio in the following circuits the output voltage is multiplied by a factor of 10. Fig. 8 shows the elertrical analog.

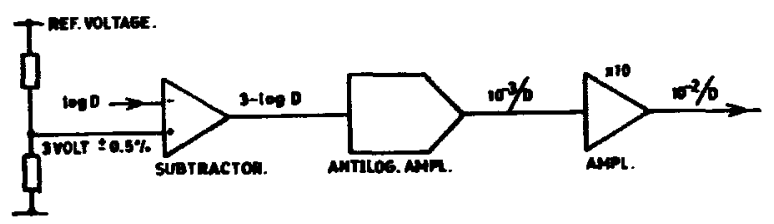

FIG.8.

\section{PERTORMANCE}

In the rinal coustruction of the analog computer performance tests in the temprature range $0^{\circ}:-5^{\circ} \mathrm{C}+10^{\circ} \mathrm{C}$ have shown accuracies close to the expected values; aprart forit $l_{1}$ : dividicte mode where the non-linearity at small values of Dexceeds the desired limit:;
The linearity of the optical dersily it; kept within the - los liat ranging from 0.01 up to 0.8 of $h$ a above this value the conformity to the ideal curve is: $\pm 1.4 \%$. In the mode of computing the natural logarithm of the optical density, lnd, the cutput excursion from the ideal curve is 1 w fron $h$ equal to 0.04 up to 0.7 ; below and abuve these values the conformity to the idieal curse is: $-1.5 \%$ and $+3 \%$ respectivgly. The dividing mode non-linearity is $t \in[$ from $h$ equal to 0.01 up to 0.6 ; above this value the conformity to the ideal curve increases up to $20 \%$ at $h$ equal to 0.9 . In the performance test carried out the output signal for the three different modes is a function of the input signal $I_{0}-I$ and the read error signal is demonetrated in per cent of the ideal figure, see fig. 9.

\section{RBFERENCE}

1. M.S. Matheson, L.M. Dorfman: Pulse Radjolysis. M.T.T. Presi, 1969. 


\section{Operating Instructions:}

\section{Installation}

1.1. Inspection

The instrument must always be placed in a vertical position to allow proper operation of a mercury-wetted relay contact set. Further it must be noted that the cooling of the instmument should be unimpeded.

\subsection{Power Requirements}

The instrument may be operated from a $220 \mathrm{~V}, 50 \mathrm{~Hz}$ ac source. A fuse of 0.25 ampere slow-blow for 220 volt operation is mounted on the rear parel.

\section{Operating Control Punctions}

The instrument front panel is provided with terminals for the XY-curve tracer, the XX-recorder, and for the digital voltmeter, and controls and switches for the adjustment and setting of the calculation modes.

\subsection{Power Switch}

The power switch turns the instrument on and off, and the monitoring lamp shows when the instrument is on voltage.

\subsection{POLARITY Switch}

The setting of the "POLARITY" switch on "+" or "-" depends on the oscillostcope photo. If the ascilloscope base line and the beginning of the light pulse are it the lower left corner of the photo, the switch setting $i_{i ;}$ "-". If the base line and the beginning of the pulse are in the upper left corner of the phato, the switch setting is "+". This results in a coordinate system with the ordinate to the left and the abscicisa al the foot of the paper of the XY-recorder.
By means of the "FUNCTION" rotary switch the computer is: aritcinot to the required mode of operation. The read-out on the XY-recorder $i$ : only dependent on the position of this switch.

\subsection{SELFCTOR Switch}

With the "SELDCTOR" rotar" switch the output terminal for the digital voltmeter is connected to the computing circuits. Besides, the digital voltmeter can be switched to two internal measuring points necessary for the operation.

But. while the $X Y$-recorder always shows the mode of operation to which the "FUNCTION" switch is tumed, the signal displayed on the digital voltmeter is not only dependent on the position of the "SELECroR" switch, but for some operation modes also or the position of the "runctIon" switch. Setting of the "SBECrop" switch to lo:h, D, and (D) -D) always gives the right figure independent of the "FuNCTION" switch. But for $10^{-2} / D,-\ln D$, and $-\ln (D \infty-D)$ the "Tuscrion" switch must be switched to the same operation mode, too.

\subsection{SCALE GALIBRATION}

By means of the "SCAL GALIBRATION" control all computer critibration $i_{\text {: }}$ performed for the actual oscilloscope photo.

\subsection{Doo-Control}

By means of the "Do"-control the limiting optical density (ID . - is adjusted.

\section{Operating Procedure}

\subsection{Galibration of the Analog Computer}

No preparation for operation is required except for connet ting the cur tracer, XY-recorder, and the digital voltmeter. It is remmended the 
a 15 minute watm-up period bie allowed for the equipment to reach a stabilized operating temprerature.

Flace the oscilloscope photo on the slide of the curve tracer with the time axis parallel to the $X$-axis and the beginning of the trace towards the operator. The $\mathrm{X}$-axis $\mathrm{i}$; the lo $\mathrm{cmll}$ long movement of the slide. With the oscilloscope base line, i.e. $100 \%$ transaission, to the right on the slide, turn the polarity switch to "-" position. With the base line to the left, turn the polarity witch to "+".

with the base line to the right on the photo, push the slide fully to the left and adjust the ringer screw on the slide to bring the base line and the start of the light pulse precisely underneath the pointer. With the base line to the left, the procedure is the opposite.

Now move the slide of the curve tracer until the pointer stays at the maximum of the trace, maximum absorption $h_{\text {max }}$. Adjust the scale factor $\mathrm{h}[\mathrm{mV}] / I_{0}[\mathrm{mV}]$ in accordance with the actual picture, i. $\epsilon$. calibrate the analog computer to the real value of $h$ relative to $I_{0}$, the non-absorbed light intensity. The value of $h$ in $a V$ is measured on the oscilloscope photo. Note that the value of $h$ displayed on the digital voltmeter is multiplied by a factor of ten. Turn "SELbCroR" to the desired function, the value of which will be displayed on the digital voltmeter. Note section 2.4 .

\subsection{Calibration of the XY-Recorder}

\subsubsection{Calibration of the X-Axie}

Turn the $X$-axis sensitivity of the $X Y$-recorder on $0.5 \mathrm{volt} / \mathrm{cm}$, and adjust the peri to the letit on the abcisisa by the offect control. The time scale on the XY-recurder is now half the time scale of the oscilloscope photo. 3.2 .2 . Calibration of the T-Axis

Plotting of 1 ):

With the "rUNCIICN" switch on 0 , turn the XY-recorder Y-axis seneitivity

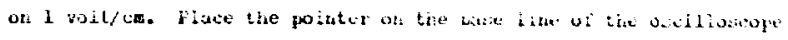

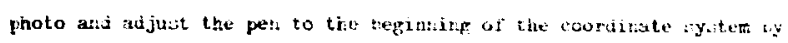
the ofiset control. Place the pointer at the maximum of the trace, $h_{\text {max }}$, and inereaze the Y-axis eenisitivity until a suitatle deflectio: is achieved. ty increasing the censitivity an of iset xultage at the zero point of the XY-rccordur and the analog compter is amplified, too. Therefore it in often inecesary to re-adjust the XY-recorder offiet and

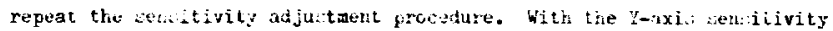

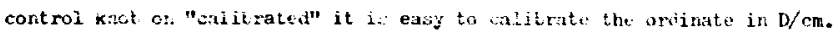
Plotting of $10^{-i^{2}} / \mathrm{D}$ :

with the "FUNCTION" switch on $10^{-3} / D$, turn the XY-recorder Y-Exis sensitivity on $1 \mathrm{rolt} / \mathrm{cm}$. Because of a high amplificstion in the computer when $D$ appraaches zero, it is recomended sot to adjust the $Y$-axis sensitivity with the pointer on the base like. Place the pointer at the maximov of the trace, $h_{\max }$, and adjust the pen to the beginning of the coordinate system with the $Y$-axis ofiset control knot. Then place the pointer on the trace appropriately close to the base line and ircrease the sensitivity until a suitable deflection is achieved. With the corresponding figures on the digital voltmeter a scaling of the orinate is rather eacy. Plotting of -1nd:

With the "PUNCTIOA" witch on -lyD turn the $X Y$-recorder I-axis sensitivity or $0.5 \mathrm{vol} t / \mathrm{cm}$. This setting of the sensitivity may be convenient for any value of the scale factor. Place the pointer at thr maximum of the trace, $h_{\text {max }}$ ard anjust the pen to the beginning of the cromolinate agstem with the Y-axi:s offet control knoh. If at higixer tencitivity is more convenient,

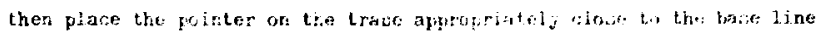

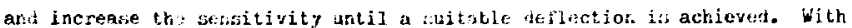


the corresponding figures on the digital voltmeter a sculing of the ordinate is rather easy.

For some settings of the rcale factor and with the pointer on the base line, i.e. $D=0$, a negutive figure may appear. This is an error due to a high amplification of a small offset voltage in the analog computer.

Flotting of $-\ln (\mathrm{D} \infty \mathrm{\infty}-\mathrm{D})$ :

Turn the "FUNCIION" switch on D and the "SEL.BCTOR" Ewitch on D... -D. Place the pointer on the trace at a position corresponding to the limiting optical density $0 \mathrm{D}_{\infty}$. Adjust the D $\infty$-potentiometer until a zero reading on the aigital voltmeter is achieved. Place the pointer at the maximum value of the trace, $h_{\text {max }}$, turn the Y-axis sensitivity on 0.5 volt/cm and the "Funcrion" switch on $-\ln \left(D_{\infty}-D\right)$. Adjust the pen to the beginning of the coordinate system with the Y-axis offset control knob.

\section{Specifications}

\subsection{Input Circuits}

The $\mathrm{x}$-input terminal $i s$ in reality the output from a lo-volt reference voltage generator feeding the $\mathrm{X}$-axis potentiometer of the curve tracer. With the curve tracer connected, the $\mathrm{X}$-axis potentiometer arm is directed to the X-output terminal.

The $y$-input terminal is the computer input. The terminal is a lo volt reference voltage generator in series with a $5 k \Omega$ lo-turn potentiometer connected to ground. The $\mathrm{Y}$-axis potentiometer of the curve tracer is incerted between the lo-volt generator and the $5 \mathrm{k} \Omega$ potentiometer, and the potentioneter arm is through the "POLARITY" switeh fed to a follower amplifier.

\section{$4 . \quad$ Output Circuits}

With the curve tracer connented to the $X$-axis input terminal the $X$-axis

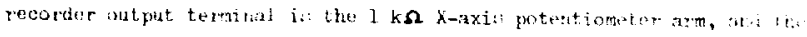
untalamed output voltage variess linearly between o mi ho volt: ponwetionally with the movemut of the slide in the itusician fipection. with the curve tracer discomected, the $x$-output terminal thoat:?

The i-axis recorder output terminai is an unbalinceli, low irpedance output which is short-circuit protected. The voltage range of the output signal is from o to lo volts. For switch positions $-1 \mathrm{rb}$ and $10^{-c} / \mathrm{p}$ the sigtial way be highter that io volis in 14 voltis), but thisi ingual iu inaccurate or mathematically undetined.

The output terminal for the aigital voltmetex (BNM-output) correspondi to the $Y$-axis recorder output terminal except for positionis lo $h$ and $D \infty-D$. Note that for positions $-\ln \pm,-\ln \left(\mathrm{D}_{\infty}-\mathrm{D}\right)$, anci $10^{-i} / \mathrm{D}$ of the "SELLEKIOR" switch the "FUNCTION" switch must be turned to the same function to get a reasonable read-out on the digital voltmeter. The voltage range isi the same as for the $\mathrm{Y}$-axis recorder output terminal. The DWM-output terminal is an unbalanced, low impedance output, which is short-circuit protected.

\subsection{Scale Factor}

A scale factor of 1.0 to 6.0 can be obtained, giving a density range of 0.08 to 1.000 for full scale deflection of the curve iracer slide, i.e. a maximum density per unit length of $0.016 \mathrm{p} / \mathrm{cm} \mathrm{j}$ s obtainable.

\subsection{Performance Accuracy}

4.4.1. Linearity of $\mathrm{x}$-axis curve tracer potentiomer: $\pm 0.4,6$. Resolution: 1.1 o/po.

4.4.2. Linearity of Y-axis curve tracer potentiomer: $-0.4 \%$. Resolution: $2 \mathrm{o} / \mathrm{on}$.

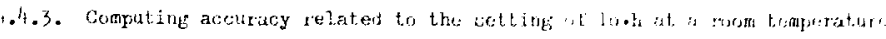
of $200^{\circ} \mathrm{U}:$

Gomputation of D: $\pm 1.5 \%$. 
Computation of $-1 \mathrm{nD}:-1.0 \%,+5.0 \%$.

Computation of $-\ln \left(D_{\infty}-D\right):-1.0 \%,+3.0 \%$.

Computation of $10^{-?} / 0$ : $\pm \%$.

Fig. 9 shows the percentage deviation as a function of $h$.

\subsubsection{Temperature Variation}

For operation from $15^{\circ} \mathrm{C}$ to $30^{\circ} \mathrm{C}$ the specifications are as follows:

Computation of D: $-1.6 \%,+3 . \%$.

Computation of $-1 \mathrm{nD} ;-1.6 \%,+3.3 \%$.

Computation of $-\ln (\mathrm{D} \infty-\mathrm{D}):-1.5 \%,+3.2 \%$.

Computation of $10^{-2} / \mathrm{D}$ : $-10 \%,+31 \%$.

\subsubsection{Testing of Accuracy}

By means of table 1 showing the accurate values it is possible to check the analog computer accuracy. Turn the "SETECTOR" switch on $10 \cdot \mathrm{h}$ and adjust with the curve tracer slide and the scale factor potentiometer a listed valie of $10 . h$. Turn the "FUNCTION" switch and the "SEIBCTOR" switch to the different computing functions and compare with the tabulated values. Corrections are only possible by trimning of the electronic circuits.

\section{Maintenance Insitrution:}

All internal potentiometers are adjusted correctly and no readjustment should be necessary for a iong time. The settings shoulit not be distialbert unl ess: there is; a definite intication that the rireuit $i_{i}$; nuctioning ircorrectly. If this happem or if a cumponent ha: beers replaced, the poten-

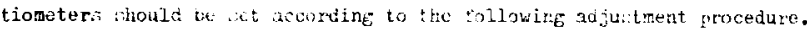
before ary corrections, allow the irstrument to warm up for at least 15 minutes.

The followine equipnent thay be reguired depending on the particular adjustment:

a) Digital voltmeter, $R_{i} \geq 0.1 \mathrm{M} \Omega$.

b) Stabilized de voltage source giving 1 volt $\pm 0.1 \%$.

c) Low frequency signal generator, $20 \mathrm{~V}$ pp.

d) Oscilloscope, normal service instrument.

The figures in parantheses refer to the measuring points on the printed circuit boards, see fig. Il the complete diagram and fig. li the power supply. Table 2 shows the connections on the printed curcuit board connectors.

\section{Power Supply}

Set the main power switeh at $\mathrm{ON}$, and allow warming-up time. Check the

$\pm 15 \mathrm{~V} \pm 1 \%$ power supply and readjust if necespary on potentiometron $\mathrm{k}$ ? and $\mathrm{R}^{3}$ respectively.

Check the $10 \mathrm{~V} \pm 0.1 \%$ reference voltage and readjust if nenejijary on $\mathrm{kl}$.

\section{Adjustront of the Optical Density Mode}

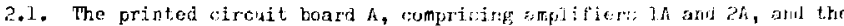

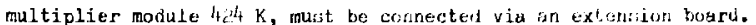


$\therefore$ Femove the stimp to the positive ingut of amplifier la and short-circuit this terminis to gromui potertial. Adjust the offict voltage to zero (2o).

2.3. Remove the strenti to the infut terminals of amplifier $2 \mathrm{~A}$ and short-cilcuit the negative terminal to ground potential. Adjust the offset voltage to zero (19). Replace the strapts.

2.4. By mean: of the curve tracer Y-axis potentiometer the output (20) of ampiifier la $\mathrm{i}_{\text {ii }}$ adjusted to 9.900 volt. By means of $R 5$ the output (19) of amplifier a is: adjusted to o.loo volt.

2.5. Remore the straps at the input terminals, feedback loop, and the output terminat of the multiplier module $424 \mathrm{~K}$. With both inputs grounded adjust the offset potentiometer Rl until zero on the output terminal. With a $20 \mathrm{~V}$ peak to peak lo $\mathrm{Yl}$ signal connected to the $\mathrm{X}$-input, and the $\mathrm{Y}$-input grounded adjust the I feed-through potentiometer R2 for minimum output. Repeat by reversing $X$ and $X$ inputs and adjust the $X$ feed-through potentiometer $R 3$ for minimum output. With $-10 \mathrm{~V}$ de on both inputs adjust the scale factor with $\mathrm{R}^{4}$ for exactly lo $\mathrm{V}$ dc output. The $X$ and $Y$ inputs refer to the multiplier module. Replace the straps.

2.6. The printed circuit board 8 , comprising amplifiers 13 and 14 , comparator AD 351 , siwitch amplifier 805 , and reed relay, mast be connected via an extension board.

2.7. Remove the straps at potentiometers $K f_{5}$ and $R$ ? and short-circuit the input terminals to ground potential. Adjust the offset voltage of amplifier 13 to neto. With the input of $R$ 7 floating, a voltage of 1.000 volt is connected to the input of $R 6$. R6 is ad justed until $434.30 \mathrm{mV}$ on the output

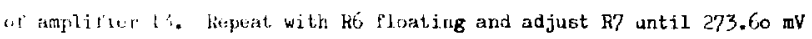
on the output. Keplace the istrapi.

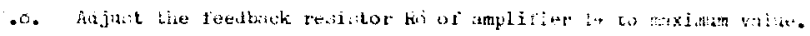
kemove the atrap, to the negative input and ahort-sirtuit thi: :...-

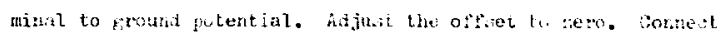

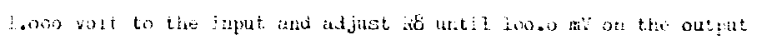
of the anigilitite. Feplace the trip.

2.9. Ly meatsi of $k 9$ aujust the reference voltuge for comperator in 351 i. ?.00 volt:i.

2.10. Fre printed circuit toard 1 , comprising amplifier: $h, \therefore$ istd 3 ant the log. module 435? must be connected via an exterision hoard,

2.11. Remove the log. module and the straps at the negative input terminals; of amulifiers 1 and 2. The amplifiers are by meani of spare resictor: coupled to an amplification factor of lo, i.e. $1 \mathrm{k}$.. at the irput and lo $\mathrm{k}_{2}$, in the feedback loop. Short-circuit the negative inputs to ground potential and adjust the offsets to zero. Remove the spare ressistors and adjust $\mathrm{R} 10$ to loo $\mathrm{k} \Omega$. The straps and the log. module are replaced, and with the curve tracer Y-axis potentiometer adjusted to make lo.h equal to 9.000 volts a voltage of 1.000 volt should be mesisurai on the output (16) of the logaritmic amplifier. An inaccuracy may he corrected by readjusting potentiometer Rlo.

2.12. Remove the strap at the lo $\mathrm{k} \Omega$ resistor at the input of amplifier 3 and short-circuit this terminal to ground potential. Ad just the of fist. volt, age to zero (29). Heplace the strap.

\section{Adjustment of the Natural logarithmic Mode}

3.1. The printert wruit board 2, ompriaing the amplidiers; $5,6,7$, ind 8 and the iog. modale 4557 , sust be connected vita un cxtention bew ril. 
3. Cerset adjutment and sdjustment of amplifiers 'i and ti ath log. module

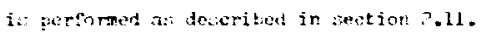

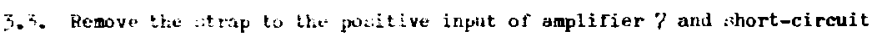
thi: termital to fround potortial. Adjust the of fset voltage to zero

(I) . Connect 1.000 volt to the ingut and adjust $R 2$ ? until 2.303 volts on the output of the amplifier. Feplace the strap.

3..4. Semove the :-trap: to the input terminals of amplifier 8 and short-cirnuit the negative input to grund yotential. Adjust the offset voltage to zero (8). Short-ciruit the poitive and negative inputs and connect a reference voltage of 1.000 volt. hujusit Rll until zero (8) on the outgut terminal. Refiace the straps.

\section{Adjustrent of the Division Misde}

4.1. The printed circuit board 3, comprising amplifiers 9, 10, 11, and 12 and $\log$. module 4357 , mu:t be connected via an extension board.

4.2. Ad justment of amplifier 9 is performed as described in section 3.4 . Adjust by means of $\mathrm{RI} 3$ the 3 volt \pm 0.59 reference voltage. The straps at the irplit terminats must be mounted during the adjustment of the reference voltage.

4.3. Adjustment of amplifiers 10 and 11 and log. module is performed as described in section 2.11. An inaccuracy at the highest output voltage may be corrected by adjusting the $100 \mathrm{k} \Omega$ potentiometer Rl5.

4.4. Kemove tree : itrap to the positive input of amplifier 12 and short-circuit this: terminal to ground potential. Adjust the offset voltage to zero (15). Connert a 1.000 volt referenice voltage to the positive input terminul and aldint me until 20 volts on the output of the amplifier. Replace the thane

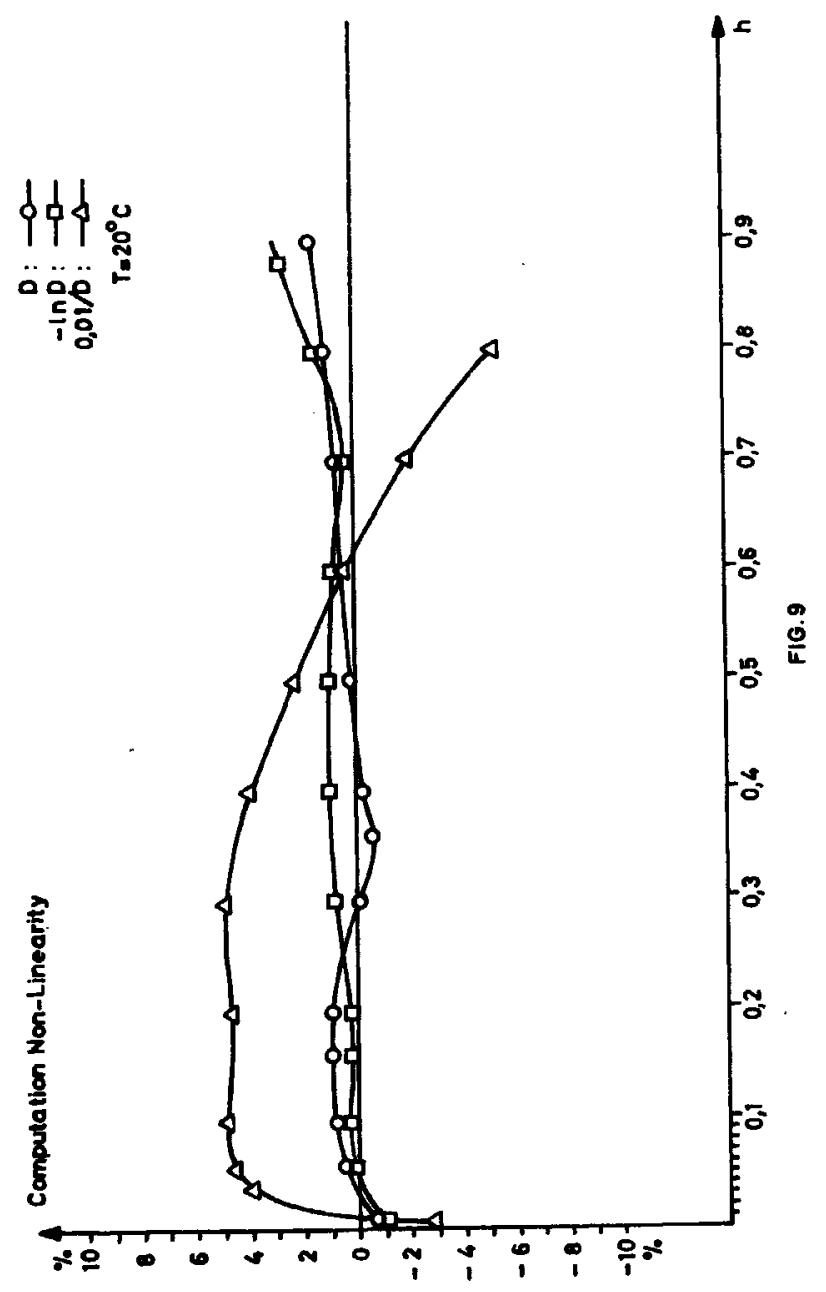




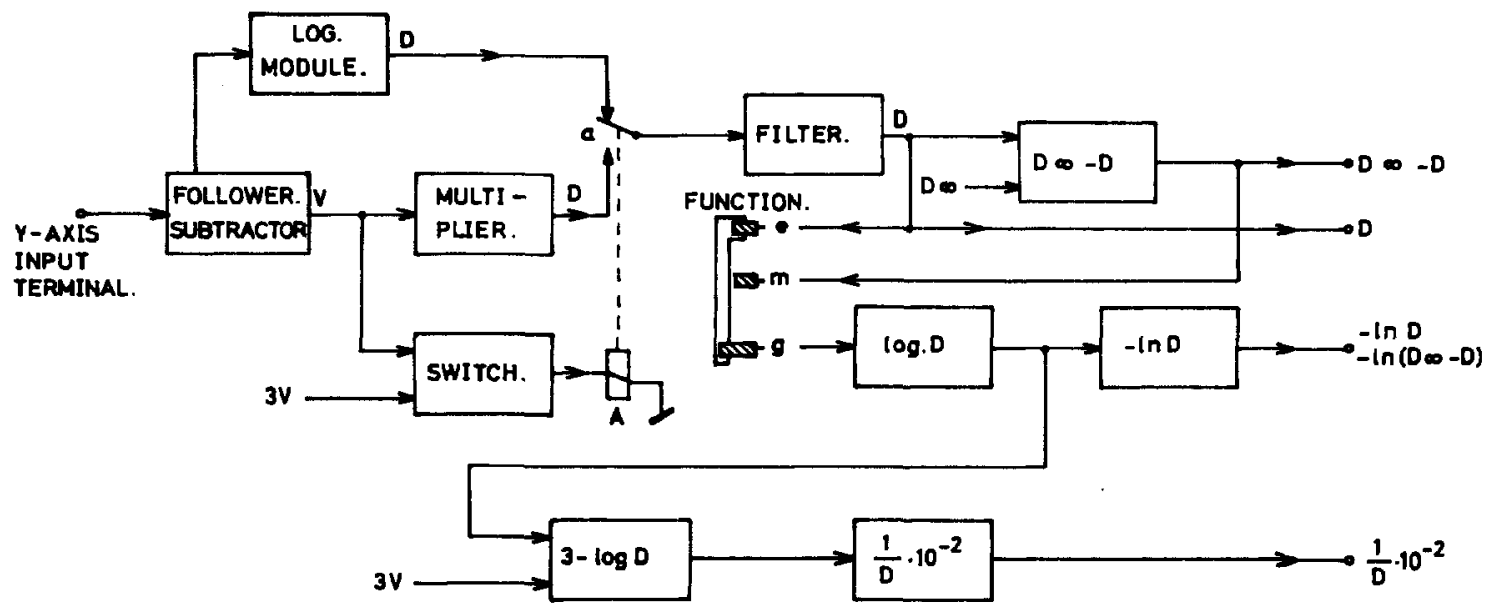

FIG.10.

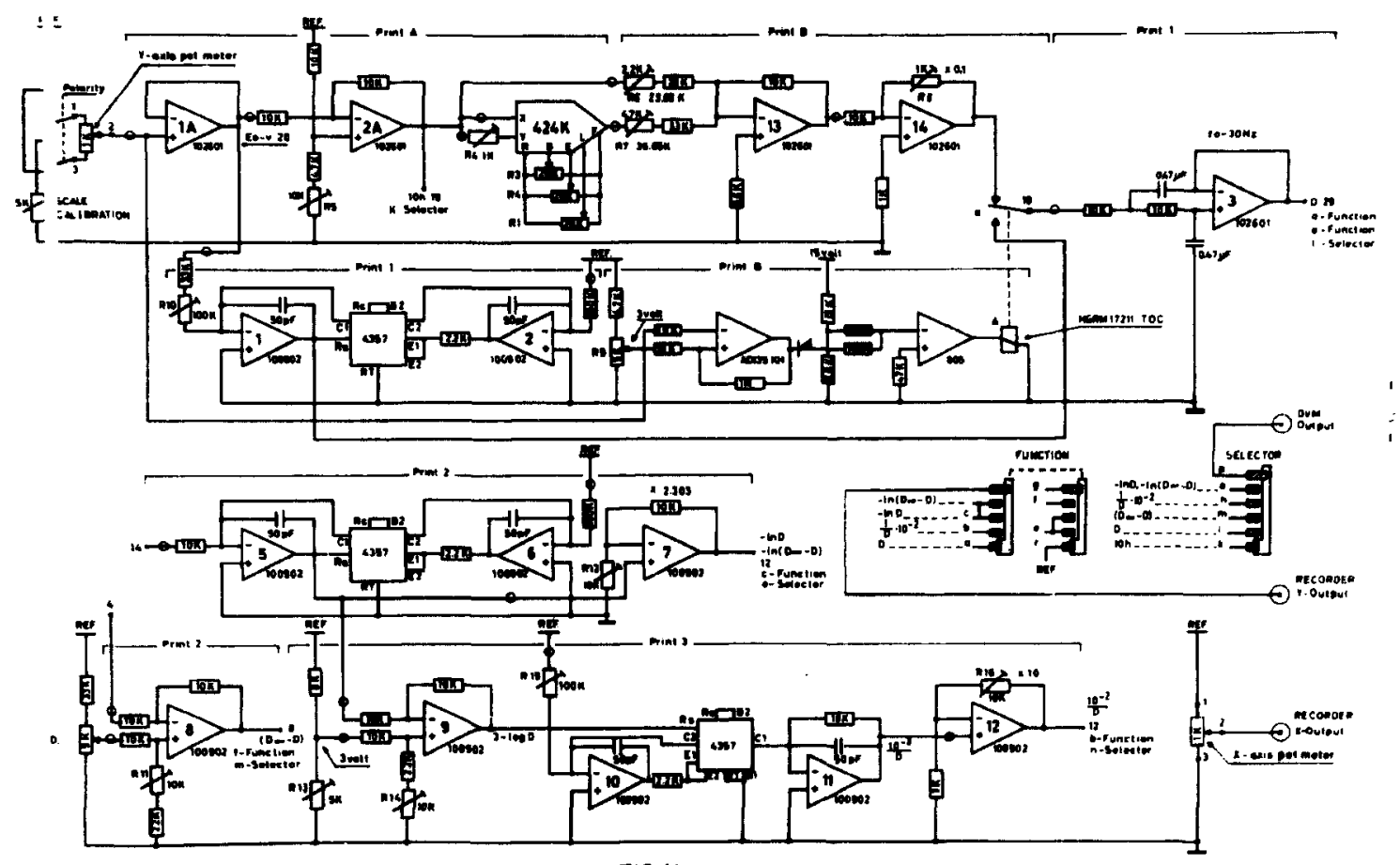




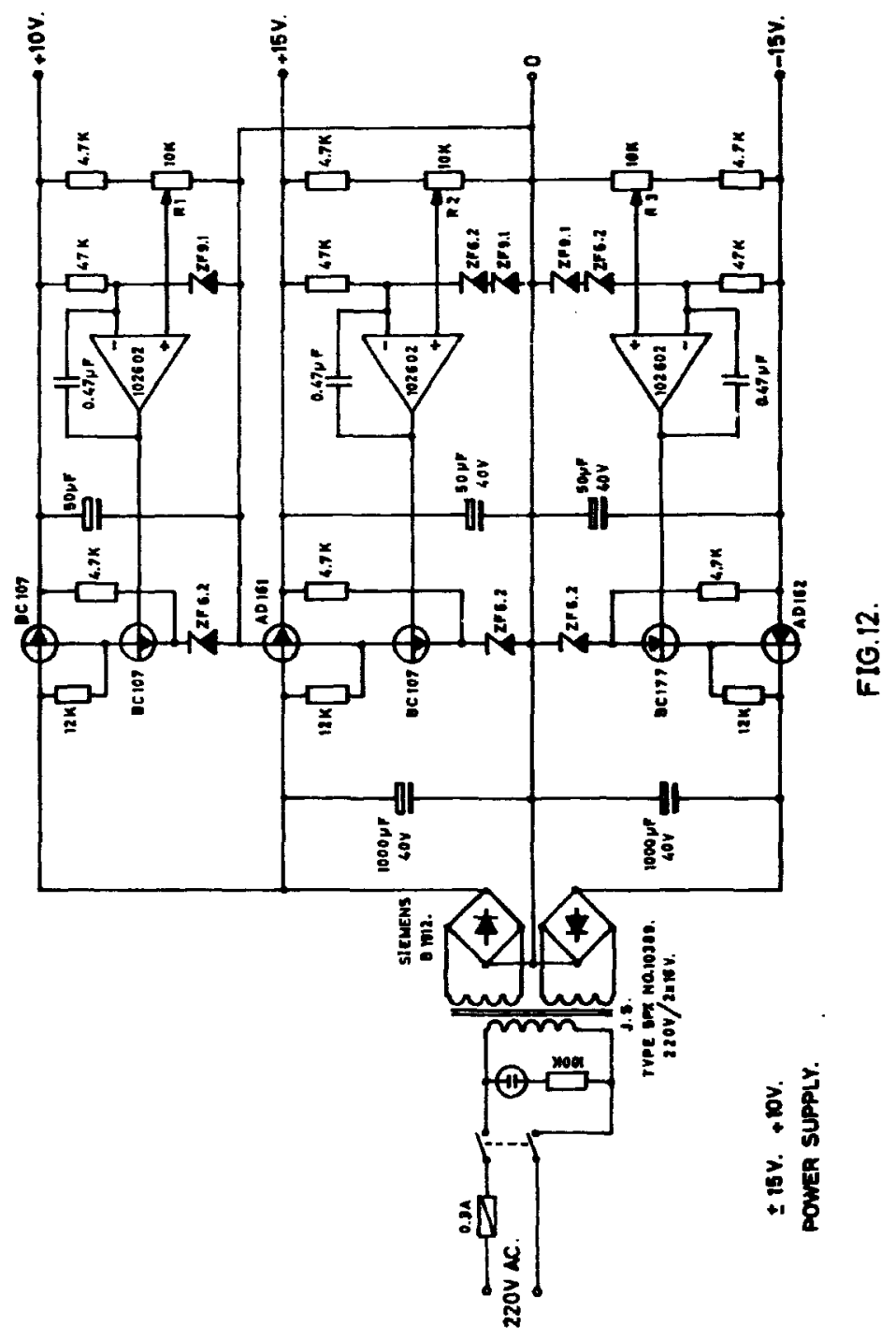

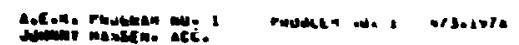

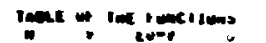
1.0.

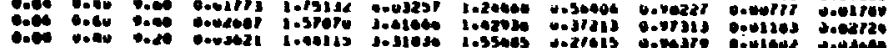

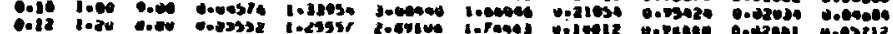

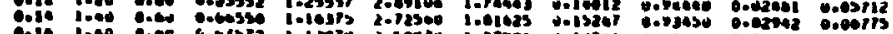

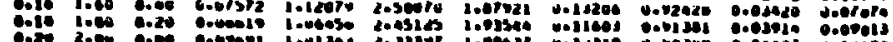

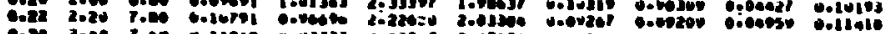

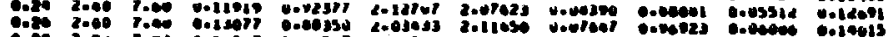

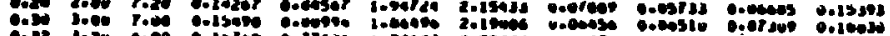

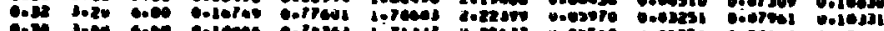
B.

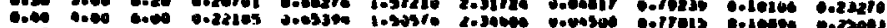

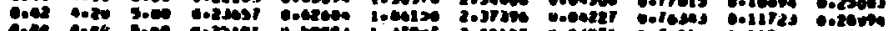
o.

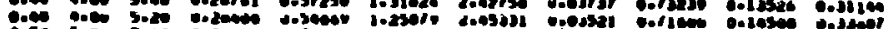

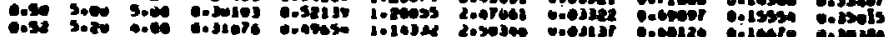

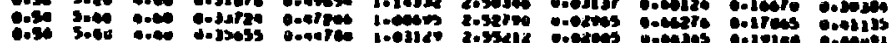

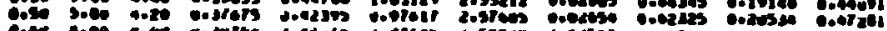

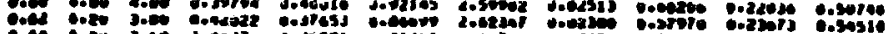

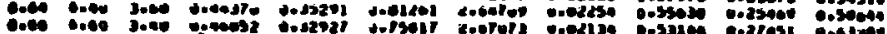

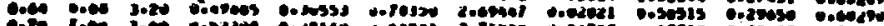

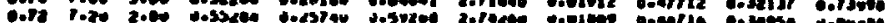

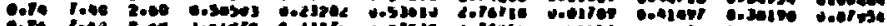

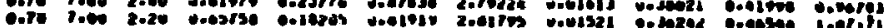
00 B. 0.60 Table?. 
Print 1 .

Print 2 .

\begin{tabular}{|c|c|c|c|c|}
\hline 10 volt & nin & 1. & it r volt & $p \perp n$ \\
\hline $\mathrm{h}$ & $" 1$ & 2 . & $-15 \mathrm{volt}$ & 11 \\
\hline+15 volt & $" 1$ & 6. & D & $" 1$ \\
\hline-15 volt & 11 & 8. & pot.meter Doo & $" 1$ \\
\hline$E_{0}-v$ & $"$ & 10. & $\mathrm{D} \infty-\mathrm{D}(\mathrm{r})$ & 11 \\
\hline O-ground & $" 1$ & 14. & lo volt & 11 \\
\hline $\log \left(E_{O}-V\right)$ & $"$ & 16. & $\ln \mathrm{D}, \quad \ln \left(\mathrm{D}_{\infty}-\mathrm{D}\right)$ & $" 1$ \\
\hline O-ground & $"$ & 24. & $E$ & $" \prime$ \\
\hline Filter output D & $" 1$ & 29. & O-ground & $n$ \\
\hline & & & $\log \mathrm{D}$ & $\|$ \\
\hline
\end{tabular}

Print 3.

Print A.

-15 volt pin 2 .

+15 volt " 3.

logD $" 6$.

$10^{-2} / \mathrm{D} \quad$ " 12 .

O-ground " 14.

lo volt " 16.

3-logD $" 2 t$.

$10^{-3} / 0 \quad " 16$
$E_{0}-v$

pin 8.

12.

-15 volt " 13.

o-ground " 16.

+15 volt " 17.

v " 19.

lo volt " 26.
Print $B$.

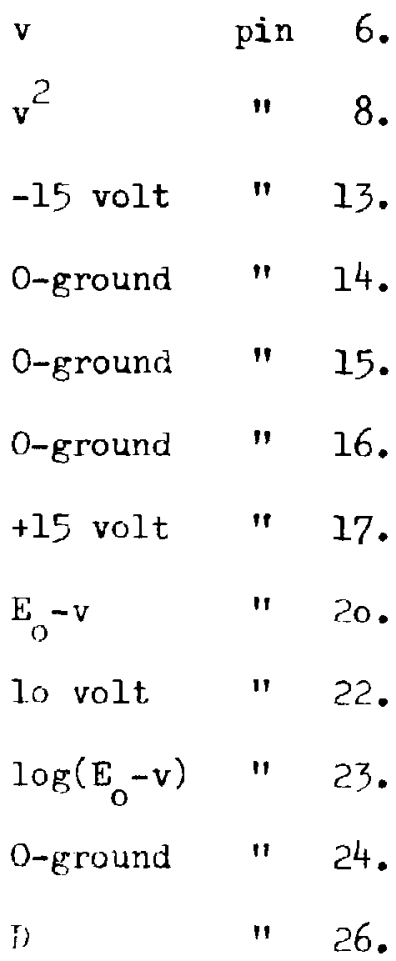

'l'able 2. 